\title{
Vestir El Cuerpo En
} Cautiverio: una práctica por revelar

\section{(Argentina 1976-1983)}

\section{María Camila Donato}

Maestrando, Universidad Nacional de las Artes - Licenciada, Universidad de Buenos Aires / camila.donato@gmail.com Orcid: 0000-0001-9490-9028

\section{Daniela Lucena}

Doctora, Universidad de Buenos Aires / daniela.lucena@gmail.com Orcid: 0000-0003-0353-3550

Enviado 30/06/2018 /Aceptado 15/08/2018 


\section{Vestir El Cuerpo En Cautiverio: una práctica por revelar (Argentina 1976- 1983)}

\section{RESUMO}

En sintonía con propuestas que tienen la intención de seguir generando conocimiento sobre el pasado reciente en Argentina, este trabajo presenta el proceso de construcción de un proyecto de investigación que parte de una perspectiva poco empleada para analizar la experiencia concentracionaria durante los años de la última dictadura militar en Argentina. Creemos que puede resultar productivo visibilizar los distintos pasos seguidos en la formulación del plan de trabajo y el modo en que diversas decisiones teórico-metodológicas llevaron a configurar un objeto de estudio que viene a interrogar un área de vacancia en la investigación académica argentina. Nos referimos, concretamente, al empleo de un enfoque que busca identificar $y$ estudiar en las narraciones, relatos $y$ testimonios sobre el cautiverio en centros clandestinos de detención, todo lo relativo a intercambios, transformaciones o mutaciones que los detenidos hayan producido en las ropas y telas que los cubrían, con la finalidad última de revelar qué sentidos pudieron tener esas acciones en el particular contexto del cautiverio.

Palavras-chave: Cuerpo-vestido, Resistencia, Cautiverio. 


\title{
Dressing The Body In Captivity: a practice to reveal (Argentina 1976- 1983)
}

\begin{abstract}
In tune with proposals that intend to continue generating knowledge about the recent past in Argentina, this work presents the process of construction of a research project that starts from a perspective that is not frequently used to analyze the experience in clandestine centers during the years of the last military dictatorship in Argentina. We believe that it can be productive to visualize the different steps taken in the formulation of the work plan and the way in which diverse theoretical and methodological decisions led to configure an object of study that comes to interrogate a vacancy area in Argentine academic research. We refer, specifically, to the use of an approach that seeks to identify and study in the narratives, stories and testimonies about the captivity in clandestine detention centers, everything related to exchanges, transformations or mutations that the detained have produced in the clothes and fabrics that covered them with the ultimate purpose of revealing what senses these actions might have in the particular context of captivity.
\end{abstract}

Keywords: Dressed body, Resistance, Captivity. 


\section{ANÁLISIS E INVESTIGACIONES SOBRE LA ÚLTIMA DICTADURA ARGENTINA}

Entre 1976 y 1983 la dictadura militar que ocupó el poder en Argentina instaló un orden político basado en el terror como modo de relación social e implantó un nuevo modelo económico que reconfiguró el escenario nacional, provocando una importante modificación en los hábitos de la población. El estado dictatorial buscó la despolitización y el debilitamiento de los lazos sociales (NOVARO y PALERMO, 2003) mediante una política económica librecambista y antiestatista combinada con el desarrollo de un plan sistemático de represión, tortura y aniquilamiento. Durante estos años, además de (y en relación con) la implantación de este nuevo orden económico y político, se desplegaron, a lo largo y ancho del país, centros clandestinos de detención donde miles de personas fueron secuestradas, detenidas, torturadas y asesinadas por las fuerzas armadas y policiales del estado.

La dictadura militar, si bien no consiguió generar la adhesión explícita de los ciudadanos, logró la pasividad de la mayoría de la población a través de la internalización del miedo, la autocensura, la parálisis y el autocontrol. En palabras de la investigadora Pilar Calveiro, especialista en temas de violencia política, historia reciente y memoria, "el campo de concentración, por su cercanía física, por estar de hecho en medio de la sociedad, 'del otro lado de la pared', solo puede existir en medio de una sociedad que elige no ver, por su propia impotencia, una sociedad 'desaparecida', tan anonadada como los secuestrados mismos" (CALVEIRO, 1998, p.147).

La represión cultural fue también parte de la acción estatal, para terminar con las llamadas expresiones subversivas y la indisciplina social (ANSALDI, 2006). Se trató de un poder concentracionario y desaparecedor que 
dispersó el terror tanto dentro de los campos clandestinos de detención como afuera, en la sociedad, que constituyó su destinataria privilegiada.

Las investigaciones y reconstrucciones historiográficas relativas a lo transcurrido en los espacios de detención clandestina durante la última dictadura militar argentina, se han centrado mayormente en los relatos respecto a la violencia física ejercida sobre los detenidos-desaparecidos en sus cuerpos-desnudos y en el análisis de los restos óseos recuperados de los cuerpos-desaparecidos. Las experiencias en cautiverio de detenidos y desaparecidos, las vejaciones a las que fueron sometidos incluso más allá de sus cuerpos, aún con un vasto recorrido allanado, siguen revelando al día de hoy espacios de vacíos por reconstruir y recuperar.

Este trabajo expone los recorridos transitados en el proceso de construcción de un proyecto de investigación que parte de una perspectiva poco empleada para analizar la experiencia concentracionaria durante la última dictadura Argentina. A partir de diversas decisiones teóricometodológicas, se ha podido configurar un objeto de estudio que interroga un área de vacancia en la investigación académica. En línea con propuestas que tienen la intención de seguir generando conocimiento sobre el pasado reciente, el enfoque empleado busca identificar y estudiar en las narraciones, relatos y testimonios sobre el cautiverio en centros clandestinos de detención, aquello relativo a intercambios, transformaciones 0 mutaciones que los detenidos hayan producido sobre o con las ropas y telas que los cubrían para intentar revelar los sentidos que pudieron tener esas acciones en el particular contexto del cautiverio.

\section{TRAJE Y CUERPO}

\subsection{LAS PRIMERAS PERGUNTAS DE INVESTIGACIÓN}

El texto que disparó los primeros interrogantes de la investigación es el relato de Marta Dillon en 'Aparecida' 
(DILLON, 2015). Hoy periodista y activa militante feminista, tenía diez años en 1976 cuando su madre fue secuestrada, detenida y desaparecida.

En 2015 Dillon editó 'Aparecida', una novela en donde conduce al lector desde el momento en que es anoticiada por el Equipo Argentino de Antropología Forense (EAAF) sobre el reconocimiento de los restos óseos del cuerpo de su madre, detenida-desaparecida treinta y cinco años antes, hasta que llega a la oficina en donde la espera la materialidad recuperada de aquel cuerpo. Hilvanando su narración a partir de las polleras, las túnicas, la campera de colores que creía recordar llevaba puesta su madre la última noche que la vio, la polera a la que le habría cortado las mangas en cautiverio, comparte los recuerdos de la vida transcurrida con su madre e intenta rearmar parte del camino que desconoció sobre sus últimos días en cautiverio:

Cristina Comandé me había hablado de eso, de la transformación de la ropa mientras la estación iba cambiando, de la primavera de octubre al verano, siempre abarrotadas en el mismo, diminuto, lugar, viendo las hojas de los eucaliptos mecerse a través de la claraboya por la que también se colaba el agua de lluvia y hasta algún cigarrillo que dejaba caer la guardia 'buena'. Mamá le había sacado las mangas a una polera. Cristina me lo contó la segunda vez que nos vimos, en el bar frente al diario donde trabajaba [...] (DILLON, 2015, p.121).

A lo largo del libro, mientras despliega su escritura en varias temporalidades que envisten de volumen la historia en desarrollo, Dillon consigue reconstruir un relato biográfico interrumpido por la violencia política, la detención y la desaparición, refiriéndose a las prendas con las que su madre se cubría. Así queda de manifiesto en el diálogo que Dillon tiene con Celeste, una profesional integrante del EAAF, en cuanto ingresa al edificio donde la esperaban los restos recuperados e identificados de su madre:

- ¿Se puede ver la ropa? 
Celeste abrió grandes sus ojos de agua y encogió un poco los hombros como si la hubiera sorprendido en falta.

- Había una bolsa con ropa, me habían dicho -insistí.

- Sí, pero está toda mezclada, no llegamos a limpiarla...

- ¿Se puede ver?

Nada podía importarme menos que la limpieza de esas prendas. Era mi mamá, era lógico que quisiera verla vestida antes que desnuda de su propia carne. Aunque las partes estuvieran separadas. Su ropa era ella. Sus polleras largas, las túnicas, sus jardineros, los collares de cuentas, los aros dorados, la campera de rayas verticales de colores que fue una obsesión para mí cuando me dí cuenta de que la ropa de mamá no tenía por qué haber desaparecido junto con ella. (DILLON, 2015, p.110).

Desde nuestra perspectiva de estudio, traje y cuerpo constituyen una unidad indisociable. Por eso, la narración de Dillon nos suscitó inquietudes referidas a las particularidades de esa unidad en aquellos cuerpos privados de su libertad: ¿cuál es el vínculo que puede establecer el sujeto con el vestido en un contexto de detención clandestina?, ¿es posible reconocer una práctica del vestir cuando el orden en donde se inscribe el cuerpo y con el cual se relaciona no prima el estado de derecho, ni se respetan las libertades individuales, los derechos civiles, siquiera humanos?, ¿qué contaría el revelar esas prácticas, o la ausencia de ellas, en la experiencia concentracionaria?, ¿podrían estas prácticas resultar, voluntaria o involuntariamente, en vínculos de solidaridad, expresiones de resistencia, gestos de supervivencia?

\subsection{APORTES DE LA SOCIOLOGÍA DEL VESTIR E INVESTIGACIONES AFINES}

Para abordar esas preguntas, decidimos elegir herramientas de la sociología de la cultura y del vestir, que entienden las prácticas vestimentarias en tanto prácticas sociales. La productividad de esos enfoques radica fundamentalmente en la comprensión del mundo social como un mundo de cuerpos vestidos, donde la acción de vestirse constituye un acto de comunicación y distinción 
central; donde el vestido expresa la naturalización de las diferencias sociales $y$ el establecimiento de un gusto culturalmente legítimo (BOURDIEU, 1988). En este sentido, la vestimenta cotidiana conforma una síntesis de las coerciones sociales (ENTWISTLE, 2002, p.14) y la imagen del cuerpo vestido constituye un símbolo del entramado de esas relaciones en las que se encuentra.

El abordaje de estudio se organizó partiendo de la idea de que la acción del vestir es una acción básica de la vida social común a todas las culturas. El vestido prepara al cuerpo para las interacciones en el espacio social, delineando una identidad que lo vuelve "apropiado, aceptable, de hecho, hasta respetable y posiblemente incluso deseable" (ENTWISTLE, 2002, p.20). Explorar las características particulares que asumen las prácticas del vestir en los espacios clandestinos de detención es uno de los objetivos centrales de la investigación.

En este sentido, es un antecedente ineludible el trabajo de la investigadora chilena Pía Montalva en 'Tejidos Blandos. Indumentaria y violencia política en Chile. 19731990' (2013). En esta investigación, Montalva reflexiona sobre la violencia política durante la dictadura de Pinochet, abordando la dimensión material de prendas y cuerpos como una totalidad, como una estructura que conceptualiza bajo la idea de cuerpo-indumentaria, para habilitar la constitución de un singular relato identitario (MONTALVA, 2013, pp.3536).

La autora trabaja el vínculo cuerpo-indumentaria siguiendo cuatro supuestos: la idea de que cuerpo e indumentaria conforman una materialidad en permanente estado de constitución; la noción de que esa materialidad cuerpo-indumentaria se inscribe en un espacio y tiempo históricos cuyos proyectos a nivel nacional piensan al sujeto de maneras disímiles; la asunción de que esa misma materialidad cuerpo-indumentaria es constituyente del relato autobiográfico que se extiende más allá de la esfera privada 
involucrando lo político, lo histórico, lo social y lo cultural; el reconocimiento de que la violencia política ejercida por el régimen mediante la fuerza y sustracción del espacio público interviene directamente sobre la materialidad de los cuerpos afectados (MONTALVA, 2013). Su lectura de la moda, las prendas específicas, los modos del vestuario epocal y sus significantes aportan a la exhaustividad de nuestra propuesta de trabajo.

Asimismo, retomamos los aportes de investigaciones que también se han desarrollado entendiendo el vestir como un hecho social y cultural. Tal es el caso de los trabajos que han estudiado el cuerpo-vestido en el marco de un entramado de experiencias artísticas de los años 80 en Buenos Aires que, leídas como una respuesta política de resistencia y confrontación, apuntaron a restituir el lazo social quebrado por el terror mediante la instauración de otras formas de sociabilidad y valores alternativos a los planteados por la dictadura militar (LUCENA, 2013; LUCENA y LABOUREAU, 2015a y b).

En el área de los estudios de género, se destaca el aporte de la socióloga Laura Zambrini que constituye a la indumentaria como su objeto de estudio para el análisis sobre la construcción de identidades. En sus estudios, Zambrini indaga respecto de los valores que se expresan en el propio cuerpo a partir de las prácticas del vestir, analizando la relación entre los usos de la vestimenta y la construcción de las identidades de género (ZAMBRINI, 2009; ZAMBRINI, 2010). Se trata de investigaciones afines a la perspectiva aquí privilegiada que, aunque referidas a otras experiencias, configuran un corpus de consulta y revisión sumamente sugerente e inspirador.

\section{EL CUERPO-VESTIDO, EN CAUTIVERIO}

Siguiendo la idea de "práctica corporal contextuada" (ENTWISTLE, 2002, p.24), que ubica al cuerpo en el centro 
del análisis, uno de los ejes centrales para la elaboración del plan de trabajo fue la identificación de prácticas en la relación de los detenidos-desaparecidos con las telas y prendas de las que disponían en cautiverio, en tanto se consideran un aspecto relevante $-y$ hasta ahora no abordado- de análisis sobre la experiencia concentracionaria. Si se habla de cuerpo-vestido, en tanto es a partir de estas prácticas que el sujeto conforma un discurso de identidad, una biografía individual y una historia social específica, resulta significativo develar otra cualidad de testimonio respecto del período de detención.

Es así que consideramos necesario definir como prácticas vestimentarias a aquellas acciones que los detenidos en centros clandestinos realizaron sobre las ropas que portaban $\mathrm{y}$, de este modo, contribuir en la reconstrucción de un relato biográfico fracturado por la detención y la desaparición. En suma, recomponer la continuidad interrumpida por dicho quiebre a partir de un abordaje en donde la indumentaria sea entendida como escritura testimonial de lo vivido durante el cautiverio.

En este punto adquiere mucha presencia la cuestión del poder y la idea de que, en toda relación de poder, el cuerpo ocupa un lugar de privilegio: no hay poder que no sea físico, que no tenga al cuerpo como blanco (FOUCAULT, 2005, p.31). Por eso, un aspecto relevante de nuestro trabajo se relaciona con la posibilidad de reconocer el cuerpo como un espacio propio e inalienable, donde los detenidosdesaparecidos en centros clandestinos pudieron desarrollar prácticas vestimentarias, interviniendo, socializando y relatando sobre las ropas que portaban. El cuerpo es asumido así en una doble dimensión: como una superficie atravesada por el poder, sobre la que la última dictadura militar desplegó técnicas de disciplinamiento y de normalización, pero, a la vez, como el medio a través del cual los detenidos-desaparecidos pudieron haber desplegado estrategias de resistencia y de superviviencia. 
Llegamos así a la hipótesis general que guía la investigación. La misma supone que, en un espacio donde las libertades han sido suprimidas y la violencia impacta en la materialidad del cuerpo-vestido, el sujeto detenidodesaparecido descubre y desarrolla acciones sobre y desde la vestimenta que lo recubre como estrategias de supervivencia y resistencia frente al poder represivo y aniquilador que lo rodea. Tal como afirma Montalva, "cuando la violencia política anula las reglas de la convivencia social y el horror tiñe lo ordinario, los rastros materiales de su ejercicio se incrustan inevitablemente en ese cuerpo vestidodesvestido" (MONTALVA, 2013, p.24). Cuáles son las marcas que quedan cuando el cuerpo está desaparecido y solo persiste la forma de su ausencia, qué dicen las acciones sobre esa ropa que portaron y transformaron los sujetos en situación de cautiverio, son cuestiones centrales que develar en la investigación.

\section{AVANCES EN LA DELIMITACIÓN 4.1 ANÁLISIS DEL CORPUS DE ESTUDIO}

Hasta el momento, se ha podido avanzar en la construcción de un corpus de análisis elaborado a partir de fuentes primarias (entrevistas e historias de vida a sobrevivientes, testimonios seleccionados del Archivo Oral de Memoria Abierta) y secundarias (bibliografía y cine documental-testimonial relativos y referidos al período histórico particular; diarios, revistas y publicaciones de la época; investigaciones en curso sobre ex centros clandestinos de detención; informes e investigaciones como "Nunca Más" Informe de la Comisión Nacional sobre la Desaparición de Personas; publicaciones de la época halladas en Clarín, La Nación, La Opinión, La Prensa, Convicción, Sur, Noticias, El Descamisado, El Caudillo, Avanzada Socialista, Nueva Hora, Somos, Gente, Para Ti, Humor, Crisis, Fierro, Primera Plana, La Maga). 
Asimismo, en base a la realización de las primeras entrevistas a sobrevivientes y a familiares de detenidosdesaparecidos, así como al relevamiento de estudios disponibles, se ha delimitado un tipo particular de prácticas del vestir que comparten una serie de características comunes y conforman el objeto de estudio privilegiado en esta investigación: se desarrollan en espacios donde el sujeto ha sido privado de su libertad; son actos voluntarios de los cuerpos-detenidos determinados por el contexto espacial donde están siendo objeto de la violencia física; son acciones que apuntan al sostenimiento de una disciplina que imprima dignidad al cuerpo-vestido detenido-desaparecido, violentado y torturado.

Para indagar en los sentidos que los propios sujetos les confieren a sus acciones sobre el vestir (o las prácticas vestimentarias) en cautiverio se parte de la perspectiva de Daniel Bertaux sobre la forma narrativa que adquiere la producción discursiva en el relato de vida. El autor postula la posibilidad de estudiar un fragmento de la realidad social e histórica externa al sujeto a partir de la singularidad de su relato biográfico, aportando la dimensión diacrónica que permite acceder a "la lógica de la acción en su desarrollo biográfico, y la configuración de las relaciones sociales en su desarrollo histórico (reproducción y dinámica de transformación)" (BERTAUX, 2005, p.11).

De este modo, las herramientas metodológicas propuestas pretenden abordar los relatos sobre las prácticas de esos cuerpos-vestidos como representaciones que constituyen modos de significación, es decir, que se destacan por su base material, su calidad de signo (DERRIDA, 1998; ARFUCH, 2008). Así, son esas formas narrativas que inscriben textualidades diversas las que deben ser analizadas en sí mismas. Importa considerarlas, no como la superficie de una esencia profunda, oculta o verdadera, sino atendiendo a su puesta en sentido y a los modos en que llegan a constituirse como narrativas 
cargadas de sentido (RICOEUR, 1996; ARFUCH, 2002a). Se busca emplear distintas perspectivas de análisis textual, discursivo y narrativo, a fin de articular un enfoque multidisciplinario que permita abordar los testimonios sin desconocer su compleja inserción en tramas de sentido en permanente reconfiguración (DERRIDA, 1998; ARFUCH, $2002 a$ y b).

\subsection{LOS PRIMEIROS CASOS}

Como señalamos, esta investigación busca develar qué dicen esas prácticas que vincularon a los sujetos con las ropas en situación de cautiverio, qué pueden relatar las técnicas y habilidades desarrolladas en relación con el vestir si son pensadas teniendo en especial consideración el espacio que habita ese cuerpo-vestido detenidodesaparecido. Es este recorrido del análisis fundamental para lograr una interpretación de estas iniciativas como medios testimoniales que sobreviven a la desaparición de los cuerpos, complejizando a su vez el relato histórico de la violencia política ejercida por la última dictadura militar. Pensar en las acciones, reflexionar sobre las prendas, reconstruir el lazo del cuerpo detenido-desaparecido con esas telas que lo rodearon, pretende referir ya no al abuso del que fue objeto sino a la resistencia de la que también pudo ser sujeto.

Siguiendo a Montalva, se reconoce que "la indumentaria articula la inserción y la pertenencia del cuerpo a un espacio y un tiempo histórico específicos" (MONTALVA, 2013, p.24) y la práctica corporal o vestimentaria y la norma que la regulan, conforman esa materialidad cuerpoindumentaria de la cual se desprende una biografía que es posible reconstituir. Por eso, los relatos y documentos referidos a las prácticas y acciones ejercidas por los cuerpos detenidos sobre la ropa que portaron en los centros 
clandestinos son las fuentes clave de la búsqueda aquí planteada.

En este sentido, se han identificado dos casos que dialogan con las preguntas de trabajo aquí delineadas y expresan con contundencia la importancia de relevar y revelar estas prácticas.

El primero es el de Martha María Brea, secuestrada, detenida y desaparecida desde el 31 de marzo de 1977. Durante el juicio por los crímenes cometidos en el centro clandestino de detención conocido como El Vesubio, Ana María Di Salvo, quien conoció a Brea cuando estuvo detenida-desaparecida durante setenta y tres días en ese centro clandestino, testificó en la audiencia de mayo de 2010 llevando consigo una bufanda que Brea le tejió con sus dedos durante el cautiverio, luego de que le dijera que sentía frío en el cuello.

El segundo es el caso de Laura Estela Carlotto, secuestrada, detenida y desaparecida desde el 26 de noviembre de 1977. Alcira Elizabeth Ríos, detenidadesaparecida en La Cacha junto a Laura, reconoció haber creído que su compañera de cautiverio había sobrevivido hasta que, en la foto de un cuerpo con un rostro desfigurado, identificó el corpiño que había regalado a Laura cuando ambas creyeron que la liberaban.

Un primer acercamiento a estos testimonios permite observar, por un lado, el establecimiento de lazos de sociabilidad y cooperación; por otro lado, la evidencia de un hecho que rectifica la palabra. De este modo, las acciones y prácticas de los cuerpos-detenidos sobre sus cuerposvestidos en el contexto de clandestinidad, como territorios para la resistencia y el ejercicio de la supervivencia, brindan también la posibilidad de explorar formas de sociabilidad generadas a partir de, o en torno a, estas prácticas y los vínculos sociales que posibilitaron. 


\section{NUEVOS INTERROGANTES Y COMENTARIOS FINALES}

Como suele ocurrir en los procesos de investigación, que no son nunca cerrados ni definitivos, en el camino de la delimitación de un corpus de análisis surgieron otras inquietudes, otros pliegues necesarios de indagar en el corto plazo. Si la práctica del vestirse expresa un tipo de relato diferente en el caso de los detenidos políticos, ¿qué ocurre por fuera de la detención, en los espacios de circulación cotidiana de la militancia? ¿Será posible reconocer prácticas vestimentarias de camuflaje en los militantes de aquella época? Si así fuera, ¿habrían sido diseñadas siguiendo los comunicados oficiales $y / o$ los cánones hegemónicos expresados en las revistas de moda de la época? Y, por último: ¿pudieron algunas de estas prácticas conservarse durante el cautiverio?

Este tipo de preguntas dirigen la mirada hacia otras zonas de la tríada cuerpo-vestido-sociedad. Una de ellas referida a los modos hegemónicos de visibilización, socialización, reproducción y otra que atiende a las representaciones de lo masculino y lo femenino en el período de estudio. Incluir esto en consideración, permitiría aportar más detalles para la exploración respecto de los vínculos afectivos y de cooperación que se pudieron generar entre los detenidos-desaparecidos en el marco de la detención clandestina.

Mientras terminamos de escribir este texto, se inaugura en el Museo Sitio de Memoria ESMA de Buenos Aires una muestra denominada "El mundial en la ESMA". Allí se exponen por primera vez objetos realizados por los detenidos-desaparecidos en ese centro clandestino cuando Argentina fue sede del Mundial 78. Un porta-documentos de cuero negro con bolsillo secreto, juegos de cartas españolas dibujadas a mano, entre otros objetos, son parte de esta exposición que presenta nuevos materiales en los que 
pueden leerse las huellas de la vida en cautiverio, así como también los rastros de una experiencia que intentó, a pesar de todo, delinear una cotidianeidad arrasada.

Son éstas las complejas piezas que hacen a la configuración de una memoria social que es aún un territorio en disputa, en tanto se redefinen allí visiones naturalizadas sobre la historia política y cultural del pasado reciente. Esperamos que el interés por las prácticas vestimentarias de los detenidos en centros clandestinos, que en su singularidad testimonial se expresan ante la ausencia de los cuerpos desparecidos, permita aportar a la reconstrucción del relato biográfico quebrado por la violencia y la desaparición en Argentina.

\section{REFERÊNCIAS}

ANSALDI, Waldo. El silencio es salud. La dictadura contra la política. En: Quiroga, H. y Tcach César (compiladores). Argentina 1976-2006. Entre la sombra de la dictadura y el futuro de la democracia. Buenos Aires: Homo Sapiens Ediciones, 2006.

ARFUCH, Leonor (comp.) Identidades, sujetos y subjetividades. Buenos Aires: Prometeo, 2002a.

ARFUCH, Leonor. El espacio biográfico. Dilemas de la subjetividad contemporánea. Buenos Aires: Fondo de Cultura Económica, 2002b.

ARFUCH, Leonor. El espacio teórico de la narrativa: un desafío ético y político. Revista Internacional de Filosofía Iberoamericana y Teoría Social, Venezuela, Año 13. Nro. 42, 2008.

BERTAUX, Daniel. Los relatos de vida. Perspectiva etnosociológica. Barcelona: Bellaterra, 2005.

BOURDIEU, Pierre. Sociología y cultura. México: Fondo de Cultura Económica, 1988.

CALVEIRO, Pilar. Poder y Desaparición. Los campos de concentración en Argentina. Buenos Aires: Ediciones Colihue S.R.L., 1998. 
DERRIDA, Jacques. Márgenes de la Filosofía. Madrid: Cátedra, 1998.

ENTWISTLE, Joanne. El cuerpo y la moda. Una visión sociológica. Barcelona: Paidós, 2002.

FOUCAULT, Michel. El poder psiquiátrico. Curso en el Collège de France (1973-1974). Buenos Aires: Fondo de Cultura Económica, 2005.

LUCENA, Daniela. Guaridas underground para Dionisios: prácticas estético-políticas durante la última dictadura militar y los años 80. Buenos Aires. Revista Arte y Sociedad, España, Universidad de Málaga, N 4, 2013.

LUCENA, Daniela y LABOUREAU, Gisela. El rol del cuerpovestido en la ruptura estética de Virus durante los últimos años de la dictadura militar. Revista Música Hodie, Goiania, Brasil, V. 15, № 2, 2015a.

LUCENA, Daniela y LABOUREAU, Gisela. Art, body and politics in the 1980s: disobedient aesthetics in the under scene of Buenos Aires. Seismopolite. Journal of Art and Politics, Noruega-Inglaterra, abril, 2015b.

MONTALVA, Pía. Tejidos Blandos. Indumentaria y Violencia Política. Chile 1973-1990. Santiago de Chile: Fondo de Cultura Económica, 2013.

NOVARO, Marcos y PALERMO, Vicente. La dictadura militar (1976-1983). Buenos Aires: Paidós, 2003.

RICOEUR, Paul. Sí mismo como otro. México D.F.: Siglo XXI, 1996.

ZAMBRINI, Laura. Modos de vestir e identidades de género: reflexiones sobre las marcas culturas en el cuerpo.

NOMADÍAS - Revista del Centro de Estudios de Género y Cultura de América Latina, Santiago de Chile, Facultad de Filosofía y Humanidades - Universidad de Chile, № 11 , 2010.

ZAMBRINI, Laura. Prácticas del vestir y cambio social. La moda como discurso. Questión - Revista Especializada en Periodismo y Comunicación, Buenos Aires, Universidad Nacional de La Plata, Vól. 1, Núm. 24, 2009. 